\title{
Walt Disney and WarnerMedia: Lifelong Rivals or Future Partners?
}

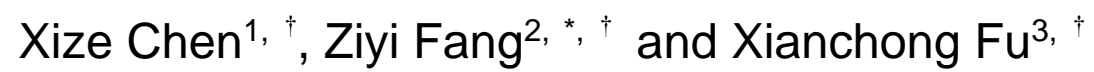 \\ ${ }^{1}$ International Department, Qingyun Experimental School, Shanghai, China \\ ${ }^{2}$ Middle School Affiliated to Huazhong University of Science and Technology, Hubei, China \\ ${ }^{3}$ Hainan Middle School, Haikou, China \\ *Corresponding author: guanghua.ren@gecacademy.cn \\ These authors contributed equally.
}

\begin{abstract}
Walt Disney and Time Warner has been in a long-term rivalry in media industry. Despite the fact that Disney's attempt to acquire Time Warner failed in 2016, it is still suspected that a conglomerate of Disney and Warner will emerge in the future. By taking a deep insight of companies' business backgrounds and history of rivalry, the paper summarizes that whether this deal will happen remains inconclusive because of the potential resistance from the regulation institutions, AT\&T and even the whole industry while it greatly benefits the two stakeholders, introducing an unprecedented, creative force to the industry. We also further infer the potential business strategies applied by Disney once it owns WarnerMedia. Using Porter's Five Forces Analysis, we conclude that the combined enterprise will have to necessarily sacrifice some established styles, while they retain high customer loyalty, relatively threatening substitutes and high entrance barrier.
\end{abstract}

Keywords: Walt Disney, Warner Media, negotiation.

\section{Introduction}

Disney acquired many other studios through mergers and acquisitions, giving them a strong presence in the market. Over time, the brand has diversified so much that it has even branched out from film studios, such as television shows, streaming services, games, merchandise and theme parks [1]. Film Studio has acquired a number of other studios, greatly increasing its presence in the market. They currently own Pixar, Marvel Studios, 20th Century Studios, etc. These are influential brands which bring in a lot of profits for Disney. Disney's closure of all theme parks and other physical attractions during COVID-19 was a huge blow to the company's finances, as most of the company's income was generated from these attractions. They also sustained a loss of employee because of it. At present, the company's business model does not experience many changes compared with it past. Figure 1 demonstrates the competitivity Disney has compared with its peers.

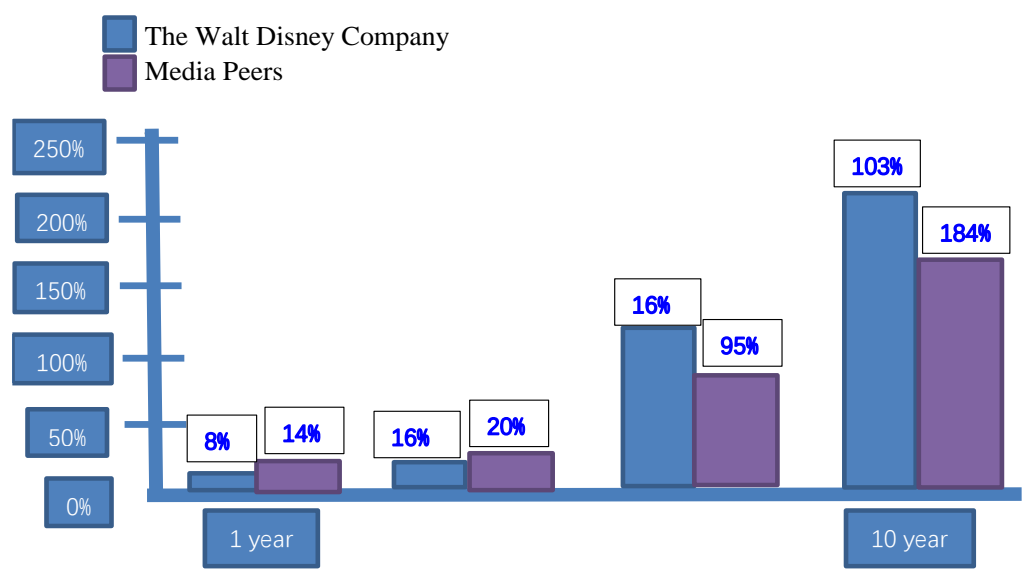

Fig 1. 1-, 3-, 5- and 10-Year TSR, DIS vs. Media Industry Peers 
Warner Bros., one of the industry's leading studios, has a number of advantages that have helped it not only protect its existing market share, but also break into new markets. Warner Bros. has been working painstakingly to develop and train its staff so that it can build expertise as they enter new markets in the future. Warner Bros. has built a reliable distribution network, allowing the company to have a strong free cash flow, which can provide the company with resources to expand into new projects [2]. At this stage, Warner Bros. has a strong financial position and is growing steadily, and the company has the wealth of knowledge and experience mentioned above. In addition, Warner Bros. now produces movies, TV shows and entertainment with the world's leading media companies, and has received many international recognitions.

Disney intended to buy WarnerMedia in 2016, which could have created a completely different future for DCEU. AT\&T ended up buying the media giant, who owns DC Comics and HBO. The $\$ 100$ billion deal with Warner media was a big business deal at the time and garnered a lot of attention [3]. But in early 2016, before the plan was finalized, Time Warner's CEO got a call from none other than Bob Iger, who asked if he would be interested in merging the two companies. Of course, films like The Expendables and Justice League were already in development when Bob Iger proposed the deal, and it is likely that they will still be released in 2017. The negative reaction to the films was sure to affect Disney and Warner Bros., so plans were canceled and the series were reconsidered [4].

Despite the fact that Disney's ownership over Time Warner has been a center of news media's reports and provoked a significantly high public concern regarding the deal, the past five years have seen relatively few researches covering such evaluations. Therefore, our assessment aims to provide credible outlook of the possibility and impacts of this acquisition, as well as insights of prospect regarding both parties, public, and the entire entertainment industry, with the ultimate purpose of providing references for future researches on similar scenarios. Our discussion begins with the description of Disney and Time Warner's Business Models, their current shortcomings and their common history as rivals, then we evaluate the possibility, values and influences and hope to foreseen the applicable strategies for Disney.

\section{Disney and Time Warner's Business Model, Weaknesses, and History of Competition}

\subsection{Disney's Business Model and Pain Point}

Walt Disney's business model is to create value by providing entertainment for people around the world. In order to maintain its competitive edge, a company must be able to meet the needs of its customers better than any other rivals in this industry. Disney's business includes four sectors: media network, parks and resorts, studio entertainment, consumer goods and interactive media. The parks and resorts bring characters, stories and franchises into life through parks and resorts, toys, applications, clothing, books and stores. Disney also maintains its extensive influence through its direct consumer facing and international business units. Consumer goods and interactive media integrate the company's technology, content and distribution platform to provide its customers with personalized experience. Among four business units, media networks account for the largest share of Disney's revenue, followed by parks and resorts [5]. Moreover, Disney's stakeholders always have very transparent, open communication. Employers and employees talk to each other in a candid way. The standards are set very high. The company encourages employees to share their ideas. If these programs are implemented, employees will receive some form of reward. This environment gives people the courage to speak out and lead, even if they have never been a leader before.

\subsection{Warner Bros’ Business Model and Pain Point}

Warner Bros. Entertainment is an integrated, broad-based entertainment company and a global leader in all areas of entertainment and all business, including creation, production, distribution, licensing and marketing. Since its inception, Warner Bros. has been the world's leading creative force, 
producing the widest range of films, including the worldwide theatrical release and exclusive premiere of HBO Max [7]. So far, Warner Bros. remains the only studio in the world to have made more than $\$ 1$ billion for 19 years in a row. It produces and distributes 18 to 22 films a year, using a business model that maximizes productivity and capital while reducing risk. Warner Bros. provides all or co-financing for its films and has global distribution rights. As a Warner Media Company, the studio has one of the most successful brand collections in the world and is at the forefront of every aspect of the entertainment industry. As Sanov said, "We are living in an unprecedented era that requires creative solutions, including this new initiative by Warner Bros."

However, Warner Bros. encounters the need to invest more in new technologies. In view of the company's planned expansion scale and companies in different regions, Warner Bros. needs to invest more funds in technology to fully integrate the process, because the current investment in technology is inconsistent with the company's vision, resulting in many deficiencies in the marketing of some products. The film industry is very volatile because the success of films can never be guaranteed. Warner Bros. must establish an internal feedback mechanism directly from the field sales team to meet these challenges.

\subsection{The History of Two Companies' Battle}

Since the 1980s, Disney has created and acquired corporate divisions to market more mature content than usually associated with its flagship, family-oriented brand. The company is famous for its film studio department, Walt Disney Studios, including Walt Disney Pictures, Walt Disney Animation Studios, Pixar, marvel studios, Lucas pictures, 20th century studios, searchlight films and Blue Sky Studios [8].

Disney wanted to acquire Warner Bros., but in 2016 AT\&T struck a $\$ 100$ billion deal, which was a huge business deal at the time, with Warner Bros. Aside from that, Warner Bros. still retain a large amount of assets, and even if some of its movies are not as popular, they are still profitable. On March 19, 20th Century Fox officially announced on Twitter that it had been acquired by Disney. In fact, Disney's biggest ever acquisition was first proposed in 2017. On December 17,2017, Disney CEO Bob Iger and News Corp. chairman Rupert Murdoch agreed to buy some of Fox's 21st century assets for $\$ 52.4$ billion, after nearly six months of antitrust scrutiny and another buyer, comcast's offer was confirmed this year. Disney currently has four major business units, namely Media Network, Amusement Park, resort, film studio, consumer products and interactive media, accounting for $43 \%$, $33 \%, 15.2 \%$ and $8.8 \%$ of total revenue in FY2017. It is expected that after the acquisition, Disney's media network business will be greatly strengthened [9].

\section{The Possibility, Value and Impacts of a Future Deal}

In 2016, the CEO of Disney Bob Iger called that of Time Warner to express his interest in purchasing Time Warner. The reason that the deal did not further was Time Warner had already reached a consensus with AT\&T a week earlier. In October 22, 2016, AT\&T came into an agreement with Time Warner on an $\$ 85$ million acquisition, and changed its name to WarnerMedia. AT\&T aimed to fully exploit Time Warner's premium resources and valuable contents with its vast distribution networking including TV, mobile and broadband distribution [10]. But it was not until 2018 that the U.S. District Judge approved the merger that was considered the biggest M\&A acquisition [11]. They have been intended to merge WarnerMedia with Discovery Inc., accelerating AT\&T's march towards media industry. The deal is expected to be closed in 2022. On the other hand, in March 20, 2019, Disney complete its merger with 21st Century Fox - the biggest acquisition after the one of BAMTech in 2016. It also obtained 30\% share of Hulu. Despite the outcome of the constant acquisitions, Disney is indubitably enlarging its domination, leading the entertainment industry with its almost monopolistic power.

Generally, this is a deal beneficial for both companies. Disney, once acquired Time Warner and its assets, will obtain ownership of CNN, Turner Sports, Warner Bros. film studio, TBS, truTV, 
Cartoon Network, TNT, and HBO; They will also be able to bring the franchises of popular characters and movies, such as Looney Tunes, Harry Potter and DC superheroes, into their archives. With all these resources, they may gain great profits not only from streaming, which is consistent with their purpose of acquiring 21st Century Fox in 2019, but also from offline services, including theme parks and merchandises. Moreover, according to Porter's Five Force Analysis of Time Warner, the threats of potential entrants have to be seen high; their rivals can make up to $81.2 \%$ of the market share, while Warner only captured 9.8\% [12]. In this case, Disney is more of a solid prop for Time Warner. Merging with Disney potentially provides Time Warner with a reliable distribution resource, given Disney's mass media networking. Last but not least, the merger of Disney and Warner may be a breaking news for the audience as it means that they might see characters in Marvel Cinematic Universe and DC Cinematic Universe showing up in the common plots.

As Warner Media currently in its process of merging with Discovery, the odds of Disney acquiring Warner Media remains indefinite. AT\&T has planned to part with Warner Media with a reported \$43 million deal once the conglomerate WarnerDiscovery is officially formed. With John Malone, the largest private landowner in the United States, giving up his voting share to push the merger, WarnerDiscovery will have the flexibility to be sold, at which time Disney, Apple, Amazon and Netflix will be potential suitors [13]. Rumors had it that AT\&T once planned to sell WarnerMedia's gaming division to pay a huge debt, but they might have found an alternative because there have been few indications of them actually selling the department, and according to a WarnerMedia scenario analysis, after computing a valuation on the telecom firm without Warner Media, it is possible to conclude that AT\&T would be worse off without the media and entertainment segment [14]. Nonetheless, because of Disney's cancellation of Infinity due to management failure and retreatment from the game industry, it could have been possible that Disney will consider purchasing WarnerMedia's game division if AT\&T has it on sale [15]. Moreover, Disney maintains the purchasing power to own DC Comics, a main rival of Marvel Comics and also one of Warner Media's filmmaking studio. However, the conglomeration of Disney and Warner Media, if formed, will pose a big threat of an almost insurmountable monopolistic hold towards other companies within the industry. With its recent acquisition of 20th Century Fox, Disney now owns over $40 \%$ of all theatrical box office releases [16], let alone the higher percentage after owning WarnerMedia. Moreover, it is also hard for the government to approve the merger of Disney and Time Warner, or it has to undertake the risk of forming a monopoly. Take the acquisition between Time Warner and AT\&T as an example, it was blocked by the U.S. Department of Justice and stagnant for nearly 2 years [11].

Nevertheless, the potential benefits from this merger would only be a bonus for both Disney and WarnerMedia. Disney has to negotiate with AT\&T-and in the not-so-distant future, with WarnerDiscovery--in the very first place to confirm if they intend to renounce the ownership; if not, it will not severely affect Disney's continuing horizontal business expansion by acquiring other companies in the future; As for WarnerMedia, despite the reported financial problem, potential downsizing, and unrevealed credit from the market, this transformative merger will incontestably form a global media powerhouse that is able to join other preeminent competitors, including Disney+ and Netflix [17]. As a result, the failure of the combination with Disney, if happened, will not strike WarnerMedia's business as it can still continue the collaboration with Discovery.

\section{The Potential Business Strategies After Acquisition}

This paper applies Porter's Five Forces model to analyze Disney's external environment in determining its business operation. This model can help analyze and determine the degree of competition and influence factors of a company in its industry. It has the advantage of being able to predict the before-and-after effects of buyers and sellers in the Disney-Warner Bros. merger, Disney's competition in the industry, the bargaining power of buyers and suppliers, the threat of substitutes, and whether there will be new entrants will be discussed in the following passage. Figure 2 demonstrates the overall structure of Porter's Five Forces. 


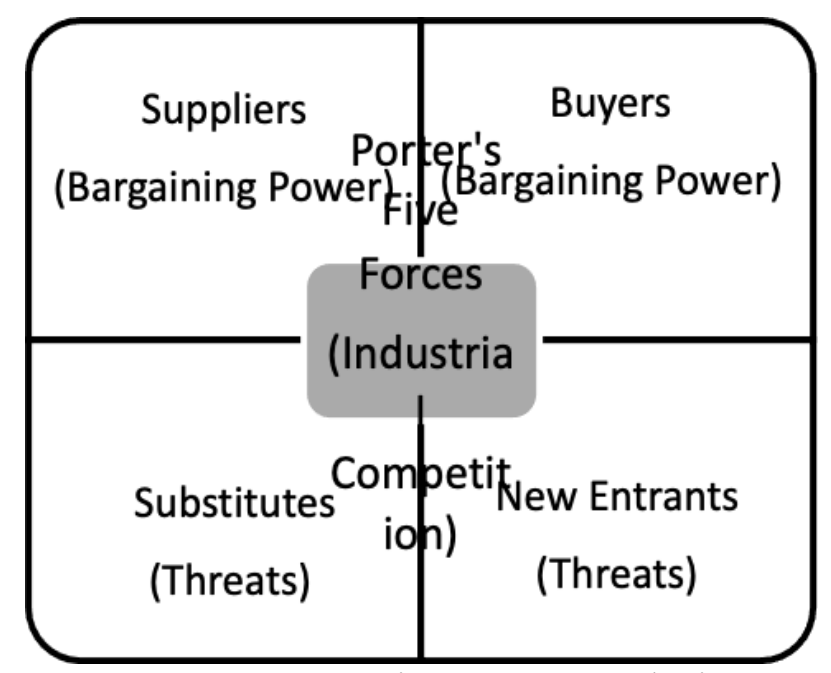

Fig 2. Porter's Five Forces Analysis

First, the competition within this industry. There are powerful companies in the movie-making industry that are very ambitious. These companies have undoubtedly intensified Disney's fierce competition with them. For example, some film production companies attach great importance to producing high-quality animated films. They are actively competing with Disney's Peters Animation Studios [18]. Walt Disney introduced their iconic cartoon character Mickey Mouse in 1928. This allowed Disney to dominate the film industry at the time, almost without competition. However, the creation of Warner Bros. animation in 1930 partly changed the situation for Disney. Disney's famous characters and Warner Bros.' main character 'Bugs Bunny' are constantly battling for animation supremacy [19]. Disney has a lot of different media competitors in different areas. Its biggest competitors are Comcast, Time Warner, 21st Century Fox, CBS and, Discovery Communications and they are proved to be the leader within this industry [20]. An acquisition of Walt Disney and Warner Bros. would be difficult because of their distinct stylistic differences. The two companies must give up part of the film production style of one party, and once the acquisition company's creation mode and film production studio must be coordinated and unified in terms of style and staff

The second factor is the bargaining power of buyers and suppliers. The bargaining power of Disney's suppliers is moderate. The medium here means that their suppliers also have very influential and famous companies, such as Philips, Nokia. Since many of their suppliers are well known, it is also challenging for Disney because it is difficult for them to easily change suppliers and find the same or better choice once they change. On the other hand, Disney's buyers have weaker bargaining power. Largely because Disney enjoys a very high reputation and social awareness. Because of the high quality of Disney's service and products, they are rewarded with high customer loyalty and publicity. They provide a very high-quality experience that customers will spend more time and money on. It is this that makes Disney customers or buyers have less bargaining power [21].

The third point of analysis is the threat posed by potential substitutes. A potential threat to Disney now is that they could be replaced someday. For example, whether some companies will create more appealing animated characters or products is unknown. However, since Disney makes movies and provides services at Disneyland that no other company can match, consumers are mostly not going anywhere else. Under this circumstance, Disney's special services may lead to higher prices, which may make consumers hesitant to buy [22]. As things stand, even if Disney acquires Warner Bros., it will be hard for its potential substitutes to overtake them. The last thing to be analyzed is the threat posed by new entrants to the industry. Thanks to the rapid growth of the Internet and streaming media in recent decades, new entrants to the film industry have not dwindled, even as production costs have been high [23]. 


\section{Conclusion}

This paper aims to consider the future relationship between Disney and Warner Bros. based on their historical relationship. The essay focuses on some historical events and competitive relationships between Disney and Warner Bros to predict the possibilities of the two companies in the future. Then estimate the possibility of their cooperation or acquisition and study of their transaction value. The odds of Disney buying Warner Bros. are not very high based on the available research. The first is that Warner Bros. has been acquired by another company. Second, even if the acquisition succeeds, Warner Bros. long film-making history makes it difficult to experiment with new styles and innovations. Moreover, Disney and Warner Bros. are both giants of film and television production, and a merger would hurt Warner Bros. 'position in the industry. Under this circumstance, the stronger voice after the acquisition will be on Disney's side. Since the styles of the two animation studios are completely different, there will be a lot of discord between ideas, pieces and production methods after the acquisition. If negotiation does not solve the problem, it can cause great trouble for both companies.

\section{Conflict of Interest}

The authors declare no conflict of interest.

\section{Author Contributions}

Z. Fang was the leader of the research team. She outlined the structure of the paper and searched for related research and news reports; X. Chen analyzed historical data and made graphs; X. Fu analyzed the company's business strategies; all authors participated in writing the paper; all authors had approved the final version.

\section{References}

[1] Disney's Linear Networks business generates most revenue and profits By MATTHEW JOHNSTON Updated October 05, 2021.

[2] Warner Bros SWOT Analysis, Competitors \& USP Published by MBA Skool Team, Last Updated: August 21, 2021.

[3] The Disney-Warner Deal that Almost Happened in 2016 Posted on May 25, 2021 by Rebekah Barton.

[4] AT\&amp;T-Time Warner Acquisition | SpringerLink Dallas, Texas and New York, New York, October 22,2016

[5] Walt Disney Business Model and Marketing Strategy Mar 24, 2015 by Brandon Gaille.

[6] HOW WALT DISNEY AND GEORGE LUCAS USED PAINFUL PAUSES TO REDEFINE THEMSELVES (Painful Pauses Can Change Your Life). Categories: All Grades, Productivity, Self-Care, Social Emotional Learning, Stories. Disclosure of Material Connection: Some of the links in the post above are "affiliate links." This means if you click on the link and purchase the item, I will receive an affiliate commission. Regardless, I only recommend products or services I use personally and believe will add value to my readers. I am disclosing this in accordance with the Federal Trade Commission's 16 CFR, Part 255: "Guides Concerning the Use of Endorsements and Testimonials in Advertising.".

[7] Warner Bros. Pictures Group Announces Innovative, Hybrid Distribution Model for Its 2021 Theatrical Slate Market Crumbs Dec 29, 2020.

[8] WARNER BROS. ENTERTAINMENT INC.

[9] What If Disney Had Bought Warner Bros - How the DCEU Would Look.

[10] Kumar B.R. (2019) AT\&T-Time Warner Acquisition. In: Wealth Creation in the World's Largest Mergers and Acquisitions. Management for Professionals. Springer, Cham. https://doi.org/10.1007/9783-030-02363-8_11. 
[11] J. Fuhrmann, B. Kryut, J. Zeiss, M. Zhang. (November 2018). Deal Logic Time Warner Inc./ AT\&T Inc. [Online]. Available: https://www.coursehero.com/file/106860492/Deal-Logic-Time-Warner-AT-T-2pdf

[12] Adamkasi (2019) Porter Five Forces Analysis of Time Warner Cable. [Online], Available: https://www.porteranalysis.com/porter-five-force-analysis-of-time-warner-cable/

[13] S. Campbell (May 2021). Disney Could End Up Buying DC As a Result of WarnerMedia Merger. [Online] Available: https://wegotthiscovered.com/movies/warnermedia-merger-disney-buying-dc/.

[14] Silva, Guilherme Da Cunha Morgado Cacela da, "The Time Warner effect", Master Dissertation, Eng., Nova School of Business and Economics, 2020.

[15] S. Timm. (May 2016). Disney's Game Division Reportedly Failed Due to Mismanagement. [Online]. Available: https://twinfinite.net/2016/05/why-disney-games-division-failed/

[16] K. Freeman. (March 2020). Disney’s Dangerous Monopoly on the Entertainment Industry. [Online]. Available: https://twinfinite.net/2016/05/why-disney-games-division-failed/

[17] (May 2021). Discovery and Warner Media: A New Streaming Powerhouse at an Attractive Valuation. [Online]. Available: https://seekingalpha.com/article/4431225-discovery-and-warnermedia-a-newstreaming-powerhouse-at-an-attractive-valuation

[18] L. Brown. (February 2019). Walt Disney Company Five Forces Analysis (Porter's) \& Recommendations [Online]. Available: http://panmore.com/walt-disney-company-five-forces-analysis-portersrecommendations

[19] R. Young. (August 2016). The History of the Disney vs. Warner Bros Feud [Online]. Available: https://www.cinelinx.com/movie-news/movie-stuff/the-history-of-the-disney-vs-warner-brosfeud/\#: :text=Walt\%20Disney $\% 20$ was\%20riding\%20high\%2C\%20with\%20no\%20competition.,music $\% 20 \% 28$ They\%20had\%20acquired\%20four\%20music\%20publishing\%20companies\%29.

[20] T. Delaney and T. Stawicki. (October 2016). The Walt Disney Company (NYSE: DIS) Sector: Consumer Discretionary [Online]. Available: https://smf.business.uconn.edu/wpcontent/uploads/sites/818/2016/12/DIS-Report.pdf

[21] A. Pratap. (April 2017). Disney Five Forces Analysis [Online]. Available: https://notesmatic.com/disneyfive-forces-analysis/

[22] Adamkasi. (December 2018). Porter's Five Forces of Walt Disney Company [Online]. Available: https://www.porteranalysis.com/porters-five-forces-of-walt-disney-

company/\#: :text=Porter's\%20Five\%20Forces\%20of\%20Walt\%20Disney\%20Company\%201,...\%205 \%20Competitive\%20Rivalry.\%20...\%206\%20References.\%20

[23] J. Dudovskiy. (March 2014). Warner Bros. Porter's Five Forces Analysis [Online]. Available: https://research-methodology.net/warner-bros-porters-five-forces-analysis/ 